\title{
Comparing community structure on shells of the abalone Haliotis midae and adjacent rock: implications for biodiversity
}

Zannè Zeeman, George M Branch, Daniel Farrell, Gavin W Maneveldt, Deborah RobertsonAndersson, Deena Pillay

\begin{abstract}
This paper concerns the effects on biodiversity of depletion 24 of the South African abalone Haliotis midae, which is a long-lived species with a large corrugated shell that provides a habitat for diverse benthic organisms. We compared community structure on $H$. midae shells with that on adjacent rock at three sites (Cape Point and Danger Point sites A and B), and at two different times of the year at one of these sites. Shells of $H$. midae consistently supported communities that were distinctly different from those on rock. In particular, three species of non-geniculate (encrusting) corallines, Titanoderma polycephalum, Mesophyllum engelhartii and Spongites discoideus were all found either exclusively or predominantly on shells, whereas another non-geniculate coralline, Heydrichia woelkerlingii, occurred almost exclusively on adjacent rock. The primary rocky substratum, however, supported a higher number of species than abalone shells. Possible reasons for the differences between the two substrata include the relative age, microtopography and hardness of the substrata; the abundance of grazers on them; and the relative age of different zones of the abalone shell, which support communities at different stages of succession. Diversity on shells was lowest in zones that were either very young or very old, in keeping with the intermediate disturbance hypothesis. The distinctiveness of shell epibiota will increase $\beta$ diversity despite having a lower $\alpha$ diversity than that of adjacent rock. Decimation of $H$. midae by overfishing therefore has implications biodiversity conservation.
\end{abstract}

Keywords: benthic, biodiversity, conservation, epibionts, shell habitat, succession

\section{Introduction}

The South African abalone Haliotis midae Linnaeus is a commercially exploited species that is seriously threatened by overfishing due to poaching (Hauck and Sweijd 1999; Hauck 2009). Because this abalone is long-lived (Newman 1967, 1968), reaches high densities in pristine populations and has a large flat shell with irregular corrugations, it provides a habitat for a diversity of organisms. Since space on hard substrata is often limited, gastropod shells constitute an important secondary settlement substrate (Steneck1986; Warner 1997; Bell 2005; Ayres-Peres and Mantelatto 2010); the loss or depletion of $\mathrm{H}$. midae may therefore have direct implications for biodiversity. This sentiment was echoed by Worm et al. (2006) who found a positive relationship between diversity and ecosystem health and reported that the elimination of species sabotages the stability and recovery potential of 
marine ecosystems. Habitat complexity influences the distribution and abundance of mobile animals (Hacker and Steneck 1990). In particular, more species occur in a given area when the structure is comparatively complex (Dean and Connell 1987). Surface roughness (rugosity) and the availability of refuges on complex surfaces are often cited as factors influencing macroinvertebrate abundance (Gee and Warwick 1994; Kraufvelin et al. 2006; Norderhaug et al. 2012). Alexander et al. (2009) identified refuge diversity as the measure that best explains spatial variability of invertebrate species richness. Gonzalez and Downing (1999) found that amphipod numbers increased in the presence of zebra mussels (Dreissena polymorpha), attributing this phenomenon to increased habitat complexity provided by the mussels, which they associated with a reduction in predation risk.

Habitat complexity may also mitigate the effects of wave action (Dean and Connell 1987; Norderhaug et al. 2012) and increase food supply (Marx and Hermkind 1985). Hacker and Steneck (1990) showed that tenacity and crypsis were important factors in habitat choice of the amphipod Gammarellus angulosus, both of these characteristics being enhanced by surface roughness. H. midae is a long-lived species (Branch and Branch 1981; Tarr 1989) and has a large shell with irregular corrugations. Because of their rugosity and complexity, abalone shells may naturally provide refuges between their ridges for algal sporelings and small mobile animals. Because of the latter, abalone shells may theoretically influence community diversity, either at the local, habitat level (a-diversity) or at larger, inter-habitat levels (bdiversity) (Whittaker 1960).

To determine the relative importance of shell microhabitat as secondary substrate, and thus its influence on localised biodiversity patterns, we compared epibiont communities developing on the shells of $\mathrm{H}$. midae with those growing on adjacent primary rocky substratum. One of the reasons that the two substrata may support different communities is that shells will, on average, be younger than the rockface. Moreover, due to the nature of the shells' development, different portions (zones) of the abalone shell will have attained different ages and will be exposed to differing levels of disturbance. This has implications for the types of organisms that are likely to occupy the shells, as the different zones will support different successional groupings of organisms. For example, non-geniculate (encrusting) corallines are generally inferior competitors for primary space (Steneck et al. 1991) due to their slow growth and are easily overgrown by foliar macroalgae

(Steneck 1986; Eager 2010). High fecundity and an extended reproductive season, however, increase opportunities for encrusting corallines to occupy vacant space (Steneck 1986; Eager 2010). Thus, if primary space becomes available on newly formed shell, or is continually created by abrasion of parts of the shell, those portions of the shell should be dominated by thin crusts, whereas on older portions of the shell where space is likely to be limited, thick crusts should dominate, and on the oldest parts of the shell, foliose algae are likely to prevail. 
Against this backdrop, we addressed two hypotheses. First, we tested whether communities on the shells of

H. midae differ from those found on surrounding primary rocky substratum. If so, this would imply that abalone shells provide a unique habitat, thereby influencing biodiversity. Second, we tested whether there are differences in epibiont assemblages on different zones of the shells of $\mathrm{H}$. midae.

\section{Methods and materials}

Sampling took place at three sites (Fig. 1): Cape Point (34_200200oS, 18_280090oE) in January 2009, Danger Point sites A (3483704700S, 1981704600 E) and B (3483705200S, 1981705100E) in January 2009 and Danger Point site A in August 2009. At each site, divers using SCUBA randomly collected abalone and scrapings from the primary bedrock between abalone, at depths of 1-4 $\mathrm{m}$. Sample sizes constituted 20 abalone and 20 rock scrapings at Cape Point, 10 at Danger Point sites A and B in January, and 20 at Danger Point site A in August.

Three different aspects were addressed using different subsets of the data. First, comparisons of community composition were based on the data for all three sites and for two different times at one of these (Danger Point A). Second, for detailed analyses of diversity, we examined only the samples taken at Cape Point in January 2009 and at Danger Point A in August 2009 because the larger numbers of samples taken then allowed more robust statistical comparisons. These samples were used to make comparisons between rock and shell communities at each site, but not for comparisons between sites because of differences in sampling dates. Third, analyses of algal succession on the abalone shells were based on samples collected at Danger Point site A in August 2009. For all samples, the area of each abalone shell was estimated as the area of a circle (pr2), with the radius being calculated as $r=0.259$ (L ? W), where $\mathrm{L}$ and $\mathrm{W}$ are the length and width measured from shell edge to shell edge using a string stretched across the contour of the shell. Rock samples were scraped from $20920 \mathrm{~cm}$ areas, with the intention of approximating the average area occupied by a reproductively mature abalone shell. In reality, the shells proved smaller than the rockscrapings, so the data were standardised per unit area for analyses. In the laboratory, the shells were scraped to remove all epibionts within each of the five shell zones as described below, and both the scrapings from the shells and those from the rocks were then sorted and all epibionts identified. Each epibiont was quantified by counting invertebrates and wet-weighing algae. Counts were later converted to wet weight by using conversions obtained by weighing subsamples of 10-100 individuals, so that analyses could be based on a common unit (wet mass per unit area). For the successional study, the shells were divided into five zones (Fig. 2) and the abundance of algal species in each zone scored as percentage cover. Zones 1, 2, 3, 4 and 5 ran successively from the youngest to the oldest portions of the shell. Zone 2 was additionally distinguished by the fact that it constituted a 'disturbed' zone where the shell is frequently rubbed against rocks (Chalmers 2002). 
The areas of each of the five zones were approximately equal, except for the growing edge (Zone 1), which was half the area of the other zones. For comparison of diversity among zones (requiring equal areas among zones), samples taken in Zone 1 were randomly combined in pairs to constitute 20 samples of comparable area to those of other zones. Although statistical analyses of zones were based on the data for individual abalone, the data were averaged and expressed per unit area for presentation of the results.

\section{Statistical analyses}

Biomass data were first transformed using fourth-root transformation to reduce the importance of dominating species, and then subjected to Bray-Curtis similarity analyses. PERMANOVA tests (Primer version 6? With PERMANOVA, Clarke and Gorley 2006; Anderson et al. 2008) were performed to determine (1) whether the community structure of the organisms found on abalone shells differed from that found in rockscrapings and (2) whether community structure differed among shell zones. For tests of community structure between rock and shells, or between shell zones, one-way PERMANOVA designs were employed, with treatment (shell vs. rock; five shell zones) being the fixed factor.

Cluster and multi-dimensional scaling (MDS) analyses were also undertaken, but as emergent patterns were similar for these two approaches, only the latter are presented. Simper analyses identified those species that contributed most to any differences among communities.

The 'Diverse' procedure in Primer was employed to compare rock versus shell samples separately for Cape Point and Danger Point site A (August 2009), in terms of total number of species, total biomass, and Margalef's (do) and Shannon-Wiener (Ho) diversity indices. These analyses were limited to within-site comparisons of rock versus shell, as comparisons among sites would have been invalidated by differences in the seasons when sampling was done. As the area of the individual rockscrapings (400 cm2) differed from that of the shells (which averaged $275 \mathrm{~m} 2$ ), the data required transformation for comparison. Transformation of biomass was simple: the data were expressed as wet weight per unit area $(\mathrm{g} 100 \mathrm{~cm}-2)$. Student's $t$ tests, or Mann-Whitney U tests (in cases where data did not meet the assumptions of equality of variance and normality required of a t test), were then undertaken for each species that occurred on both abalone shells and rockscrapings, to determine whether any differences in biomass existed. Statistica 9 was used for these tests. Comparisons of diversity, evenness and richness could not validly be undertaken in a similar manner because area affects these measures, and the area of rockscrapings was greater than that of abalone shells. Consequently, six randomly selected rockscrapings were discarded to reduce the total area of rockscrapings to a value comparable to that of all shell samples combined. As the resultant comparison was based on a pair of individual values (pooled diversity for all replicates), there was no variance in the data. An adjusted manual t test (as per Zar 1998) was consequently 
performed to determine whether the diversity values between treatments were statistically different.

The 'Diverse' procedure in Primer was also employed to determine the number of species present in each shell zone and the diversity per shell zone as per ShannonWiener and Margalef's diversity indices. One-way analyses of variance (ANOVA) were performed to test whether significant differences existed between substrata or among shell zone, with both regarded as fixed factors, and a set at 0.05. Unless otherwise stated, data are presented as means $\pm 1 \mathrm{SE}$.

\section{Results}

Comparison of shell and rock communities MDS ordinations (Fig. 3) showed a clear distinction between shell and rock communities on all but one occasion [Danger Point site A in January 2009: Pseudo-F9 $=1.71, \mathrm{P}($ perm $)=0.06$ ]; Danger Point site B in January 2009: Pseudo-F9 $=4.8, \mathrm{P}($ perm $)=0.001$; Danger Point site A in August 2009: Pseudo-F19 = 8.5, P(perm) = 0.05; Cape Point in January 2009: Pseudo-F19 $=15.5, \mathrm{P}($ perm $) \backslash 0.0001)$.

Focussing only on the two data sets with large sample sizes $(n=20)$, Simper analyses affirmed these results, showing $84 \%$ dissimilarity between shell and rock communities at Cape Point and 90.6 \% dissimilarity at Danger Point site A.

At Cape Point (Fig. 4a), the geniculate coralline red alga Jania cultrata and the foliose green algae Ulva spp. Were found only on shells. Two geniculate coralline red algae (Amphiroa capensis and Arthrocardia flabellata) and three non-geniculate coralline red algae (Titanoderma polycephalum, Spongites discoideus and Mesophyllum engelhartii) had significantly higher biomass on shells than on the adjacent rocky substratum. Only the non-geniculate coralline alga Heydrichia woelkerlingii was significantly more abundant on the adjacent rock than on shell. The species contributing most to the dissimilarity between shell and rock communities were the corallines A. capensis, A. flabellate and $\mathrm{H}$. woelkerlingii.

At Danger Point site A (Fig. 4b), several patterns emerged. First, as was the case at Cape Point, H. woelkerlingii was predominantly found on rock, although there was high variability in the data, while the other nongeniculate corallines ( $T$. polycephalum, S. discoideus and M. engelhartii) were substantial contributors to the shell community and were comparatively rare on the adjacent rocky substratum. Second, relatively large species (ca. 20-100 mm), which included the hermit crab Paguristes gamianus, the winkle Oxystele sinensis, the sea cucumber Pseudocnella insolens and the green alga Codium stephensiae were predominantly associated with adjacent rocky substratum. Third, small species (ca. 1-5 mm) such as the gastropod Eatoniella nigra and small mobile crustacean grazers (several species of amphipods and isopods) were relatively equally distributed between the two substrata. 
At Cape Point, neither biomass nor any of the two diversity indices were significantly different between the two substrata when all taxa were combined. However, when animals and algae were separated, the two groups exhibited opposite patterns, with all three indices being greater on rock than shell for animals (although significantly so in only one case), while the reverse was true for algae, with values being significantly greater on shell than rock in all instances (Fig. 5). At Danger Point site A, similar qualitative patterns emerged, although levels of significance differed. For animals and algae combined, all three indices were significantly greater on rock than shell.

Similarly, for animals alone, values on rock were always significantly greater than for shell. For algae alone, biomass was not significantly different between the substrata, but the number of species was significantly greater on shell than rock (Fig. 6). Analyses of Margalef's Index (data not shown) revealed the identical trends and patterns of significance as the data for number of species.

\section{Algal succession on shell zones}

Significant differences in community structure existed among zones on the abalone shells [Pseudo-F4,19 $=4.722, \mathrm{P}($ perm $)=0.001]$, and pairwise PERMANOVA tests showed that these were attributable to zones 5 and 4 being significantly different from one another and from other zones ( $\mathrm{P} \backslash 0.01$ in all cases).

Simper analysis indicated that the species contributing $90 \%$ to the difference in communities among shell zones were coralline algal species (Fig. 7). In Zone 1, the youngest zone on the growing edge of the shell, the dominant species was the thin non-geniculate coralline alga M. engelhartii, occupying $20.6 \%$ of the zone. In Zone 2, the disturbed zone where the shell was rubbed against rock, the non-geniculate encrusting coralline alga, T. polycephalum, was the most abundant algal species, occupying $32.0 \%$ of the zone. Zones $3-5$ were dominated by the geniculate coralline alga A. flabellata, which occupied as much as $36.9 \%$ of the zone. However, in zones 3 and 4 , other species of coralline contributed more evenly to the per cent cover abundance. The total number of species, Margalef's index and the Shannon-Wiener index of diversity (Fig. 8) were lowest in zones 1, 2 and 5 and highest in zones 3 or 4 . All indices were significantly different among zones (number of species F4,19 $=2.68$, $\mathrm{P}=0.04$; Margalef's index F4,19 = 2.69, $\mathrm{P}=0.04$; Shannon-Wiener index F4,19 = $6.44, \mathrm{P} \backslash 0.001)$.

\section{Discussion}

Molluscs such as abalone that have a large foot and possess fixed home scars physically occupy space on rocky substratum, but their shells provide an alternative habitat. Our central finding was the detection of significant differences in community structure between shell and rock substrata, which were consistent between sites and times. Both biomass and diversity were consistently greater on rock than shell for animals whereas the opposite was true for algae. 
When the two were considered together, the outcome depended on the relative contributions of algae and animals. In general, shell communities were characterised mostly by algae whereas rocky substratum was characterised mainly by invertebrates. These results clearly demonstrate that abalone shells increase habitat diversity and habitat complexity by providing an alternative, secondary habitat for a host of organisms. They confirm the finding of a number of previous studies (e.g. Steneck 1986; Warner 1997; Bell 2005; Smyth and Roberts 2010), but we are the first to demonstrate this for the abalone H. midae.

With one notable exception (H. woelkerlingii), coralline algae, and in particular nongeniculate corallines, benefitted from their association with abalone shells. Additionally, distinct successional patterns emerged from the manner in which corallines were distributed across the abalone shells. Of the non-geniculate corallines, M. engelhartii, a relatively fast-growing species, was clearly the pioneering species. Given the comparatively poor ability of thin, fast-growing crusts to compete by overgrowth, they generally require free space (Steneck 1986; Maneveldt and Keats 2008) such as that provided by recent shell growth or physical disturbance. Conversely, geniculate corallines, specifically A. flabellata, were the climax species on abalone shells, dominating the older, less disturbed zones. Competitive superiority among encrusting algae is achieved when one species overgrows another, with thicker crusts generally being competitively superior to thinner crusts (Steneck 1986; Steneck et al. 1991; Keats and Maneveldt 1994; Keats et al. 1994; Maneveldt and Keats 2008). If space is seldom renewed and thus becomes limiting (as in older, undisturbed shell zones), thicker, slowergrowing, competitively superior crusts should become more abundant (Maneveldt and Keats 2008). T. polycephalum and S. discoideus are comparatively thick, slower growing species that are competitively superior to M. engelhartii, and so understandable these thicker species dominated over M. engelhartii in comparatively older zones. S. discoideus is also a common occupant of the shells of another gastropod, the winkle O. sinensis (Maneveldt, unpublished data).

There are several possible reasons for the differences between communities on shells and rocks. Firstly, H. midae can be considered a foundation species as defined by Bruno and Bertness (2001, p. 201), that is, a species that creates 'a spatial refuge from environmental stress and/or predation, which can increase the fitness of individuals occupying the habitat and can positively affect populations of associated species'. H. midae facilitates species diversity by increasing the heterogeneity of the environment and providing a secondary substratum for settlement. Its shell surface is highly rugose with radiating ridges, so it is likely to provide refuge for the sporelings of algae, where they will be relatively free from grazing. Traits such as density, cover and morphological complexity can all influence the ability of facilitators to benefit other species (Bruno and Bertness 2001). The importance of $\mathrm{H}$. midae as a foundation species is increased by the fact that it is comparatively large and long-lived, and aggregates at high densities (Newman 1967, 1968). Secondly, H. 
midae shells are softer and more porous than adjacent rock and can therefore also be inhabited by boring organisms such as Polydora spp. Shell borers use chemomechanical means of boring into shells through abrasive action using either radulae or bristles on shell softened by acid; most are unable to bore into primary bedrock (Haigler 1969). In our study, the shell borers Polydora spp. were found only on H. midae shells, contributing to species richness there. Thirdly, because the shell constitutes part of a living, growing organism, different positions on the shell will differ in age, offering opportunities for species characteristic of different stages of succession to occupy different parts of the shell. Moreover, taken as a whole, the shell will be younger and more transient than the rock face. Both factors will provide more opportunity for algae at a range of successional stages, whereas the stable rock face is more likely to be dominated by a smaller suite of climax species (Connell and Slatyer 1977).

Diversity is likely to be affected by substratal stability (Worm et al. 2006), which will be influenced by (a) the longevity of the structure, (b) frequency of disturbance and (c) intensity of the disturbance. H. midae can survive for at least 30 years (Newman 1968), but primary bedrock is older by many orders of magnitude. Consequently, H. midae shells may support a higher proportion of early successional species, particularly as portions of the shell will be very young. To a certain extent, disturbance will be linked to age, as the likelihood of disturbance will increase with age. However, Zone 2 of the shell spans a range of ages but would have been consistently the most disturbed portion because it is rubbed against adjacent shells and rocks. Frequent, lowintensity disturbances have been shown to increase biodiversity (Lubchenco and Menge 1978; Sousa 1979a, b). Both predation and grazing affect biodiversity in this manner (Flint and Goldman 1975; Menge 1976). Where grazer densities are high and grazing is intense, biodiversity is decreased (Hargrave 1970; Maneveldt et al. 2009). Thus, highest biodiversity is found at intermediate levels of disturbance (Lubchenco and Menge 1978). As mentioned above, H. midae shells provide a refuge where grazing will be less intense than that on adjacent rocky substratum. This will reduce the extent to which algal succession is interrupted on the abalone shell.

Overall, diversity increased and then decreased with the age of the different zones. The youngest portions of the shell were generally dominated by a single pioneer species, yielding low diversity. Zones of intermediate age housed a more even spread of species and thus a greater diversity. Thicker, competitively superior climax species of corallines dominated on older zones of the abalone shells, decreasing the biodiversity. This is in keeping with an initial build-up of diversity as colonisation proceeded and then a decline as a few species became increasingly dominant, as Connell and Slatyer (1977) have recorded for boulder fields. The resultant pattern follows that of the intermediate disturbance hypothesis (Connell and Slatyer 1977; Connell 1978; Sousa 1979b) in being domed; but the underlying causes are different. Rather than being related solely to the frequency and intensity of disturbance, diversity in our study was also influenced by the age of the substratum, with low 
diversity values on very young surfaces where colonisation is at an early stage, highest values on surfaces of intermediate age where succession has progressed further but competition has not reached a point where some species have ousted others, and lowest diversity on the oldest portions where competitive overgrowth and shading reduce diversity once again. It was anticipated that Zone 2 would have lower species diversity than Zone 1 due to the greater level of disturbance in Zone 2. This was, however, not the case as species in Zone 2 were more uniformly abundant, whereas Zone 1 was dominated almost exclusively by M. engelhartii. This may be because disturbance in Zone 2 is not sufficient to eliminate T. polycephalum. In support of this view, Steneck (1986) reported that thick crusts were the most disturbance resistant of the three morphological states he described for encrusting corallines.

\section{Conclusions}

Haliotis midae shells influence diversity in various ways. First, in terms of adiversity, H. midae shells do not have greater biodiversity than adjacent primary rocky substratum. Secondly, due to the presence of distinct species assemblages on abalone shells, the combined presence of both shells and rock will add to the local bdiversity, so that collectively they enhance local community diversity. Thirdly, because portions of abalone shells are young or disturbed by abrasion, they provide opportunities for early colonists that would otherwise be excluded by competition. Given that H. midae once occupied up to $50 \%$ of primary rocky substratum in areas occupied by pristine populations, its decimation by overfishing clearly has community-level implications over and above the effects on stock sustainability.

\section{Acknowledgments}

Funding was provided by the National Research Foundation (NRF) of South Africa, the Marine Biology Research Centre, the University of Cape Town and an Andrew Mellon Foundation grant to George M. Branch. Many divers assisted with the sampling, and special thanks are due to Andrea Plos. Associate Professor Astrid Jarre is warmly thanked for her practical advice. Edward Hill is thanked for his patience and help with the map and figures. The constructive improvements suggested by two anonymous reviewers are much appreciated. 


\section{References}

Alexander TJ, Barrett N, Haddon M, Edgar G (2009) Relationships between mobile macroinvertebrates and reef structure in a temperate marine reserve. Mar Ecol Prog Ser 389:31-44

Anderson MJ, Gorley RN, Clarke KR (2008) PERMANOVA for primer: guide to software and statistical methods. PRIMER-E Ltd, Plymouth, p 214

Ayres-Peres L, Mantelatto FL (2010) Epibiont occurrence on shells used by the crab Loxopagurus loxochelis (Anomura: Diogenidae) on the northern coast of Sao Paulo, Brazil. Zoologia 27:222-227

Bell JJ (2005) Influence of occupant microhabitat on the composition of encrusting communities on gastropod shells. Mar Biol 147:653-661

Branch GM, Branch M (1981) The living shores of Southern Africa. Struik, Cape Town

Bruno JF, Bertness MD (2001) Habitat modification and facilitation in benthic marine communities. In: Bertness MD, Gaines SD, Hay ME (eds) Marine community ecology. Sinauer Associates, Sunderland, pp 201-218

Chalmers R (2002) An investigation into the feeding biology and factors influencing the population dynamics of Terebrasabella heterouncinata (Polychaeta: Sabellidae), a problematic tubedwelling polychaete in farmed abalone in South Africa. MSc thesis, Rhodes University, South Africa

Clarke KR, Gorley RN (2006) Primer v6: user manual/tutorial. PRIMER-E Ltd, Plymouth, p 190

Connell JH (1978) Diversity in tropical rain forests and coral reefs. Science 199:1302-1310

Connell JH, Slatyer RO (1977) Mechanisms of succession in natural communities and their role in community stability and organization. Am Nat 111:1119-1144

Dean RL, Connell JH (1987) Marine invertebrates in an algal succession. III. Mechanisms linking habitat complexity with diversity. J Exp Mar Biol Ecol 109:249273

Eager RC (2010) Documenting the association between a nongeniculate coralline red alga and its molluscan host. MSc thesis, University of the Western Cape, South Africa 
Flint RW, Goldman CR (1975) The effects of a benthic grazer on the primary productivity of the littoral zone of Lake Tahoe. Limnol Oceanogr 20:935-944

Gee JM, Warwick RM (1994) Metazoan community structure in relation to the fractal dimensions of marine macroalgae. Mar Ecol Prog Ser 103:141-150

Gonzalez MJ, Downing A (1999) Mechanisms underlying amphipod responses to zebra mussel (Dreissena polymorpha) invasion and implications for fish-amphipod interactions. Can J Fish Aquat Sci 56:679-685

Hacker SD, Steneck RS (1990) Habitat architecture and the abundance and bodysize-dependent habitat selection of a phytal amphipod. Ecology 71:2269-2285

Haigler SA (1969) Boring mechanism of Polydora websteri inhabiting Crassostrea virginica. Am Zool 9:821-828

Hargrave BT (1970) The effect of a deposit-feeding amphipod on the metabolism of benthic microflora. Limnol Oceanogr 15:21-30

Hauck M (2009) Crime, environment and power: revisiting the abalone fishery. S Afr J Crim Justice 22:229-245

Hauck M, Sweijd NA (1999) A case study of abalone poaching in South Africa and its impact on fisheries management. ICES J Mar Sci 56:1024-1032

Keats DW, ManeveldtG(1994) Leptophytum foveatum Chamberlain\& Keats (Rhodophyta, Corallinales) retaliates against overgrowth by other encrusting algae. $\mathrm{J}$ Exp Mar Biol Ecol 175:243-251

Keats DW, Matthews I, Maneveldt G (1994) Preliminary studies on competitive relationships and coexistence in a guild of crustose algae in the eulittoral zone, Cape Province, South Africa. S Afr J Bot 60:108-113

Kraufvelin P, Salovius S, Christie H, Moy FE, Karez R, Pedersen MF (2006) Eutrophication-induced changes in benthic algae affect the behaviour and fitness of the marine amphipod Gammarus locusta. Aquat Bot 84:199-209

Lubchenco J, Menge BA (1978) Community development and persistence in a low rocky intertidal zone. Ecol Monogr 59:67-94

Maneveldt GW, Keats DW (2008) Effects of herbivore grazing on the physiognomy of the coralline alga Spongites yendoi and on associated competitive interactions. Afr J Mar Sci 30:581-593 
Maneveldt GW, Eager RC, Bassier A (2009). The effects of long-term exclusion of Cymbula oculus (Born) on the distribution of intertidal organisms on the rocky shore at Kalk Bay. Afr J Mar Sci 31:171-179

Marx J, Hermkind W (1985) Factors regulating microhabitat use by young juvenile spiny lobsters, Panularis argus: food and shelter. J Crust Biol 5:650-657

Menge BA (1976) Organization of the New England rocky intertidal community: role of predation, competition, and environmental heterogeneity. Ecol Monogr 46:355393

Newman GG (1967) Reproduction of the South African abalone, Haliotis midae. Invest Rep Div Sea Fish S Afr 64:1-24

Newman GG (1968) Growth of the South African abalone, Haliotis midae. Invest Rep Div Sea Fish S Afr 67:1-24

Norderhaug KM, Christie H, Andersen GS, Bekkby T (2012) Does the diversity of kelp forest fauna increase with wave exposure? J Sea Res 69:36-42

Smyth D, Roberts D (2010) The European oyster (Ostrea edulis) and its epibiotic succession. Hydrobiologia 655:25-36

Sousa WP (1979a) Experimental investigations of disturbance and ecological succession in a rocky intertidal algal community. Ecol Monogr 49:227-254

Sousa WP (1979b) Disturbance in marine intertidal boulder fields: the nonequilibrium maintenance of species diversity. Ecology 60:1225-1239

Steneck RS (1986) The ecology of coralline algal crusts: consequent patterns and adaptive strategies. Ann Rev Ecol Syst 17:273-303

Steneck RS, Hacker SD, Dethier MN (1991) Mechanisms of competitive dominance between crustose coralline algae: an herbivore mediated competitive reversal. Ecology 72:938-950

Tarr RJQ (1989) Abalone. In: Payne AIL, Crawford RJM (eds) Oceans of life off Southern Africa. Vlaeberg, Cape Town, pp 62-69

Warner GF (1997) Occurrence of epifauna on the periwinkle, Littorina littorea (Linnaeus), and interactions with the polychaete Polydora ciliata (Johnston). Hydrobiologia 355:41-47 
Whittaker RH (1960) Vegetation of the Siskiyou Mountains Oregon and California. Ecol Monogr 30:279-338

Worm B, Barbier EB, Beaumont N, Duffy JE, Folke C, Halpern BS, Jackson JBC, Lotze HK, Micheli F, Palumbi SR, Sala E, Selkoe KA, Stachowicz JJ, Watson R (2006) Impacts of biodiversity loss on ocean ecosystem services. Science 314:787790

Zar JH (1998) Biostatistical analysis. Prentice Hall, NJ, p 663 


\section{Captions for figures:}

Fig. 1: Map of the south-west coast of South Africa, indicating (1) the geographic range of Haliotis midae

from Cape Columbine on the west coast to Port Elizabeth on the south coast, (2) the commercial fishing

zones A-G, and (3) the sampling sites at Cape Point and Danger Point (insets).

Fig. 2: Abalone shell zonation patterns. Zone 1 is the youngest portion of the shell and Zone 5 the oldest.

Zone 2 constitutes an area that is abraded by rubbing against rocks or other shells.

Fig. 3: MDS ordination between shell and rock community structure at (a) Danger point A in January, (b)

Danger Point B in January, (c) Danger Point A in August and (d) Cape Point in January. Each data point

represents one sample; $n=10$ per treatment for (a) and (b) and 20 for (c) and (d).

Fig. 4: Average biomass (g10o $\mathrm{cm}-2484+1 \mathrm{SE} ; \mathrm{n}=20$ ) of species found on shell and on rock at (a) Cape Point

and (b) Danger Point. Mann-Whitney U tests: ${ }^{* *} P<0.0001,{ }^{* *} P<0.001$ and ${ }^{*} P<$ 0.05 ; + indicates

species that were present on one substratum and absent on the other. Error bars are $+1 \mathrm{SE}$; “abs" refers to a

species ${ }^{e e}$ absence.

489 Fig. 5: Characteristics of communities on abalone shell and adjacent rock at Cape Point in January 2009: (a)Biomass, (b) Total number of species, (c) ShannonWiener diversity index, for all species combined (left),

animals (centre) for algae (right). Statistical significance for adjusted t-tests ( $t$ ) and Mann-Whitney U tests

(U), ${ }^{*} P<0.05,{ }^{* *} P<0.001,{ }^{* * *} P<0.0001, \mathrm{~ns}=$ not significant. Error bars are +1 SE. Error bars are not

indicated for total number of species, Margalefes species richness and ShannonWiener diversity index as

data were pooled (see Methods), and thus there was no variance in the data.

Fig. 6: Characteristics of communities on abalone shell and adjacent rock at Danger Point site A in August

2009: a) Biomass, (b) Total number of species, (c) Shannon-Wiener diversity index, for all species combined

(left), animals (centre) and algae (right). For further details see caption to Fig. 5 .

Fig. 7: Percentage cover of the most abundant algal species in each shell zone, arranged from the youngest to 
501 the oldest zone. Error bars are $+1 \mathrm{SE}$.

Fig. 8: Diversity of communities among shell zones represented by (a) the total number of species, (b)

Margalef"s species richness index, and (c) Shannon-Wiener diversity index. Error bars are $+1 \mathrm{SE}$. 


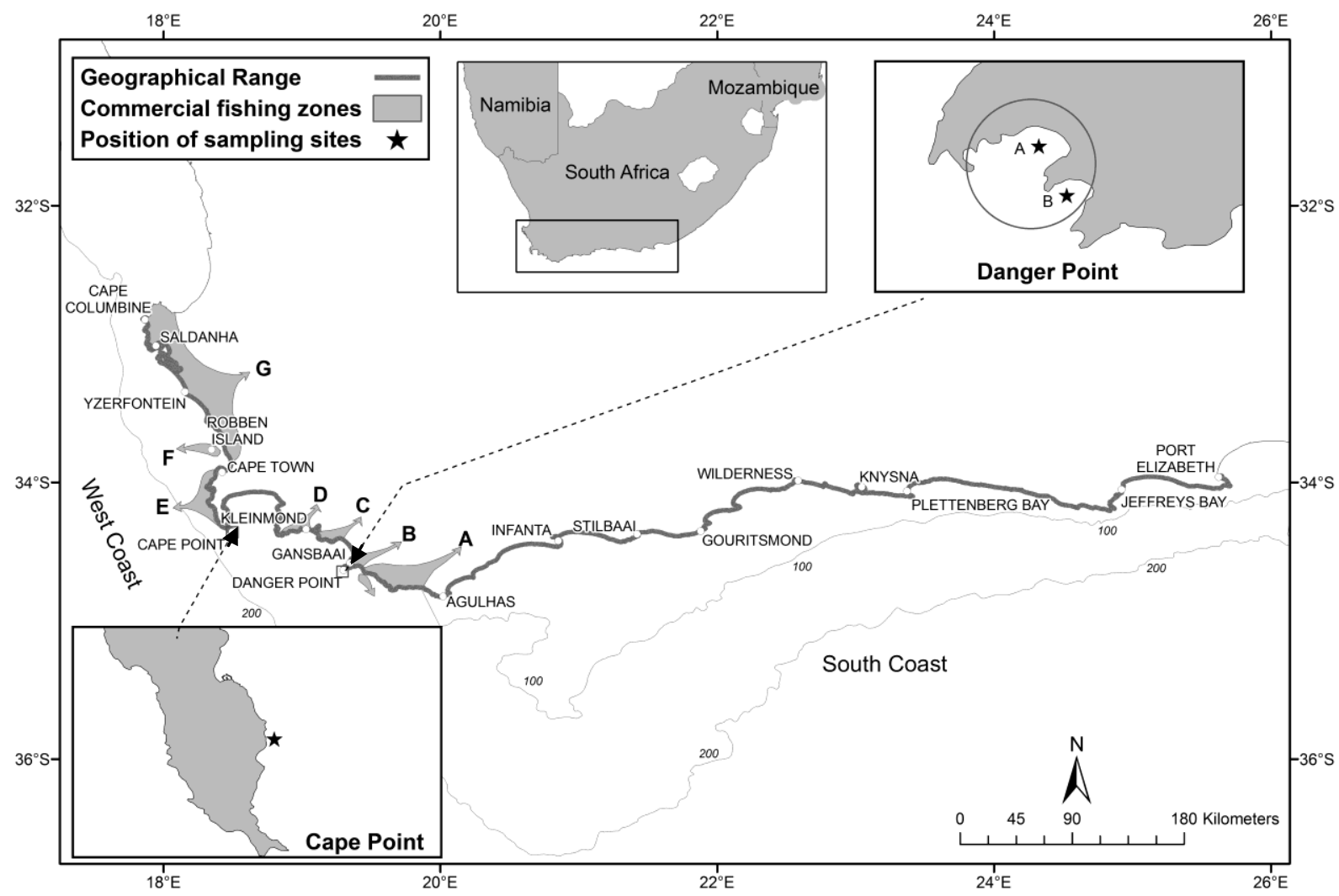

Fig. 1: 


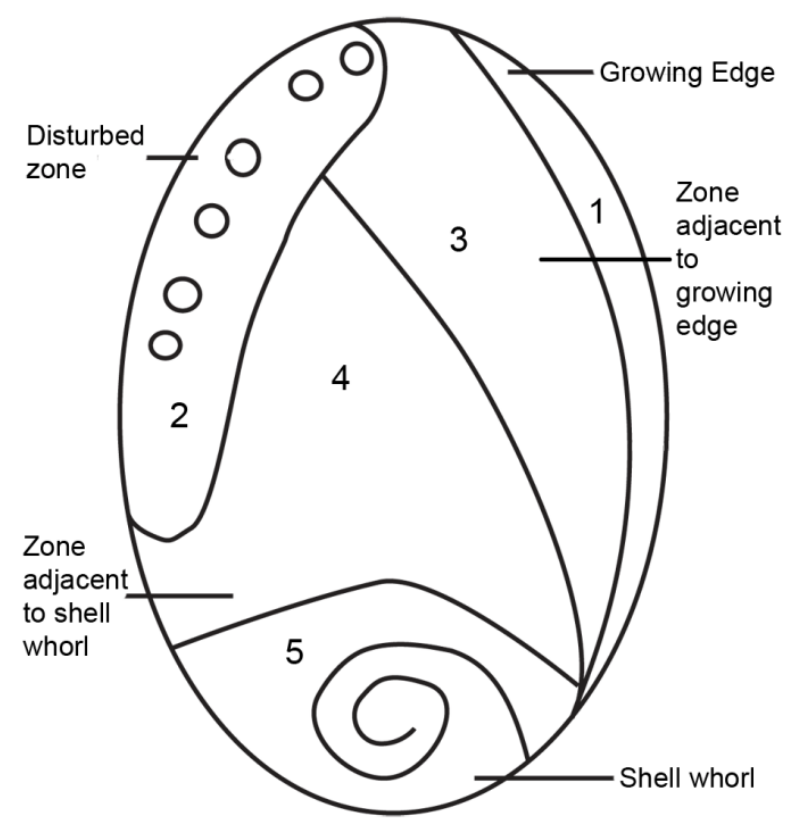

Fig. 2: 


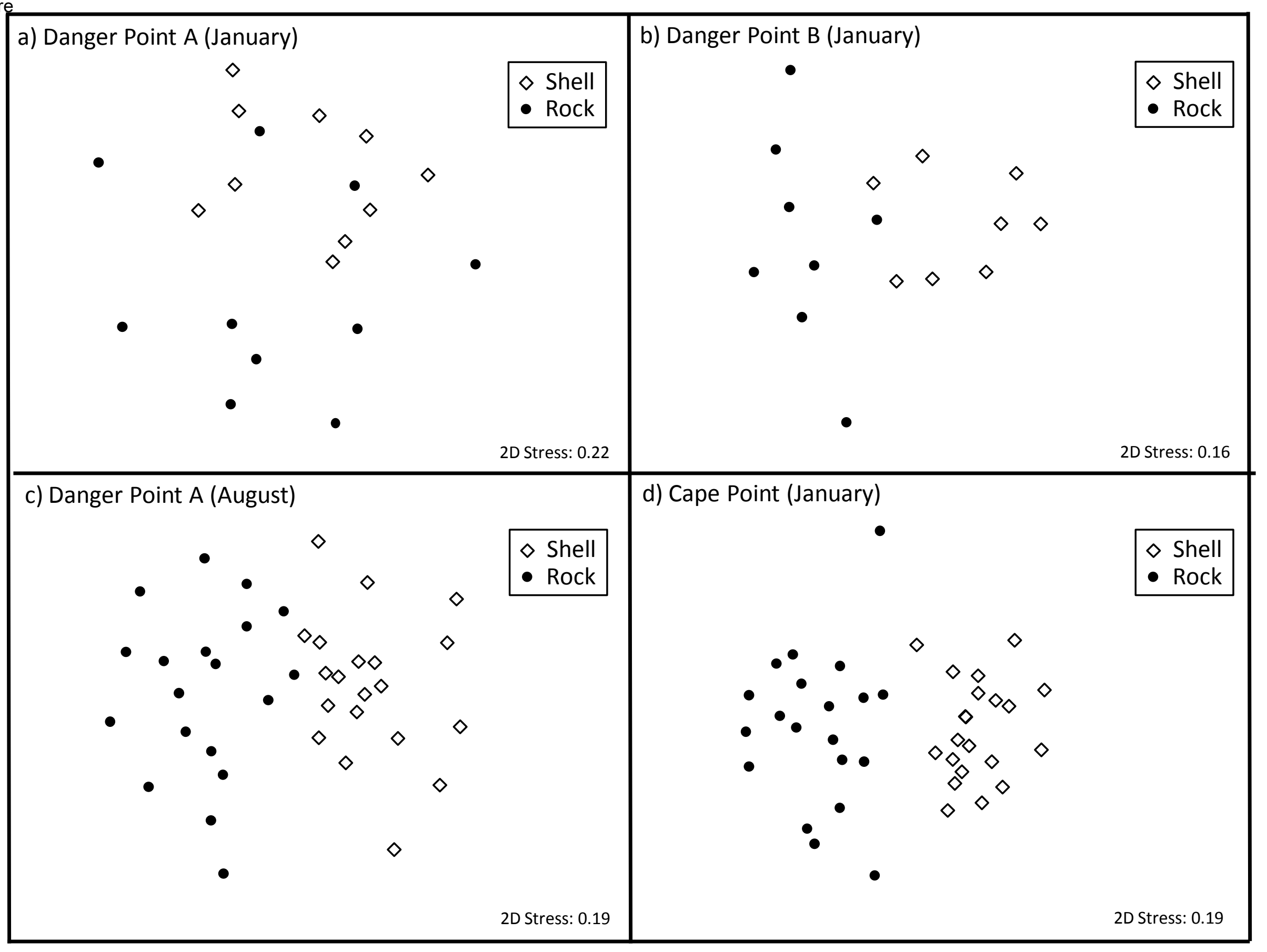

a) Danger Point A (January) 


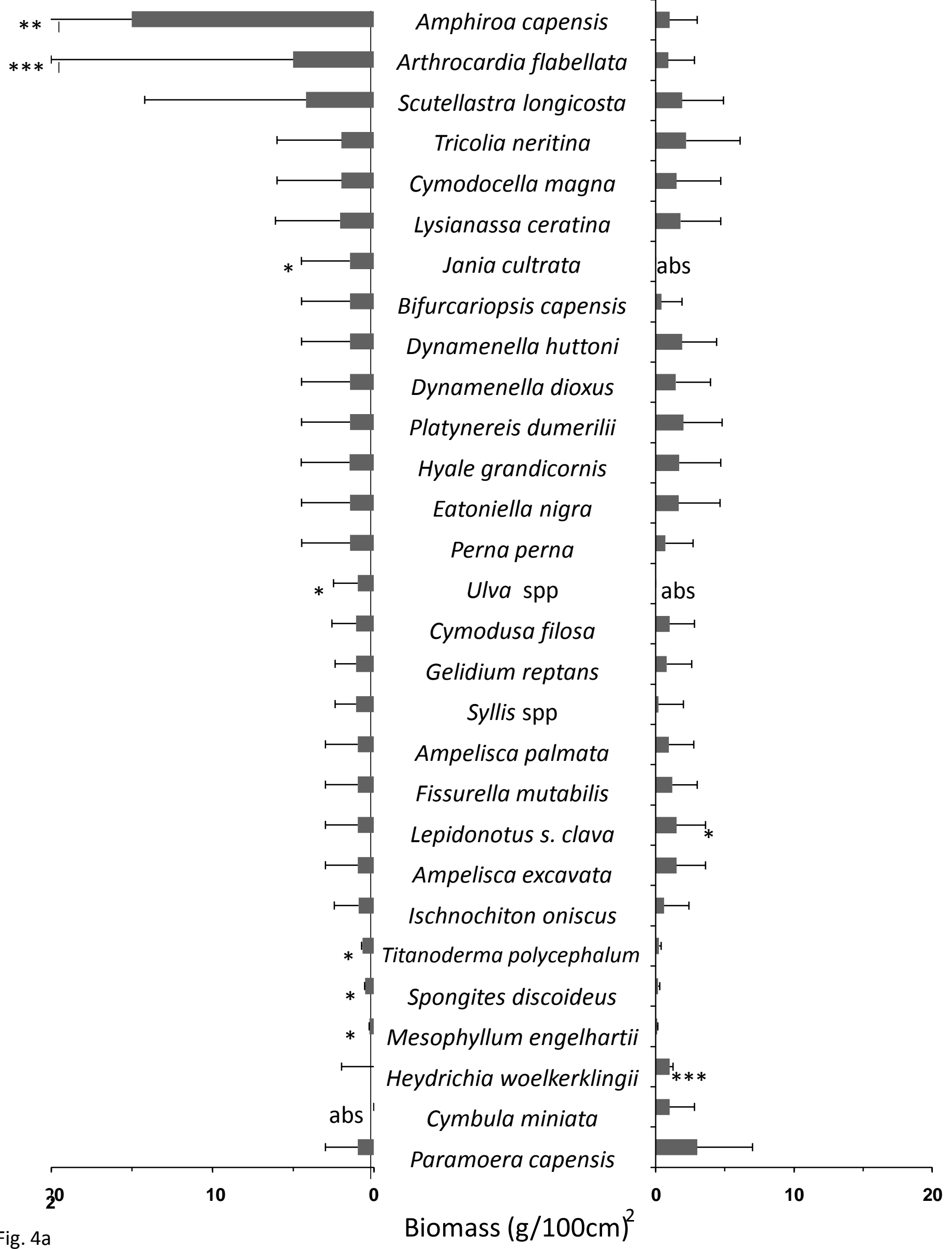

Fig. 4a

Amphiroa capensis

Arthrocardia flabellata

Scutellastra longicosta

Tricolia neritina

ymodocella magna

Lysianassa ceratina

Jania cultrata

Bifurcariopsis capensis

Dynamenella huttoni

Dynamenella dioxus

Platynereis dumerilii

Hyale grandicornis

Eatoniella nigra

Perna perna

Ulva spp

Cymodusa filosa

Gelidium reptans

Syllis spp

Ampelisca palmata

Fissurella mutabilis

Lepidonotus s. clava

Ampelisca excavata

Ischnochiton oniscus

Titanoderma polycephalum

Spongites discoideus

Mesophyllum engelhartii

Heydrichia woelkerklingii

Cymbula miniata

Paramoera capensis

Biomass $(\mathrm{g} / 100 \mathrm{~cm})^{2}$ 


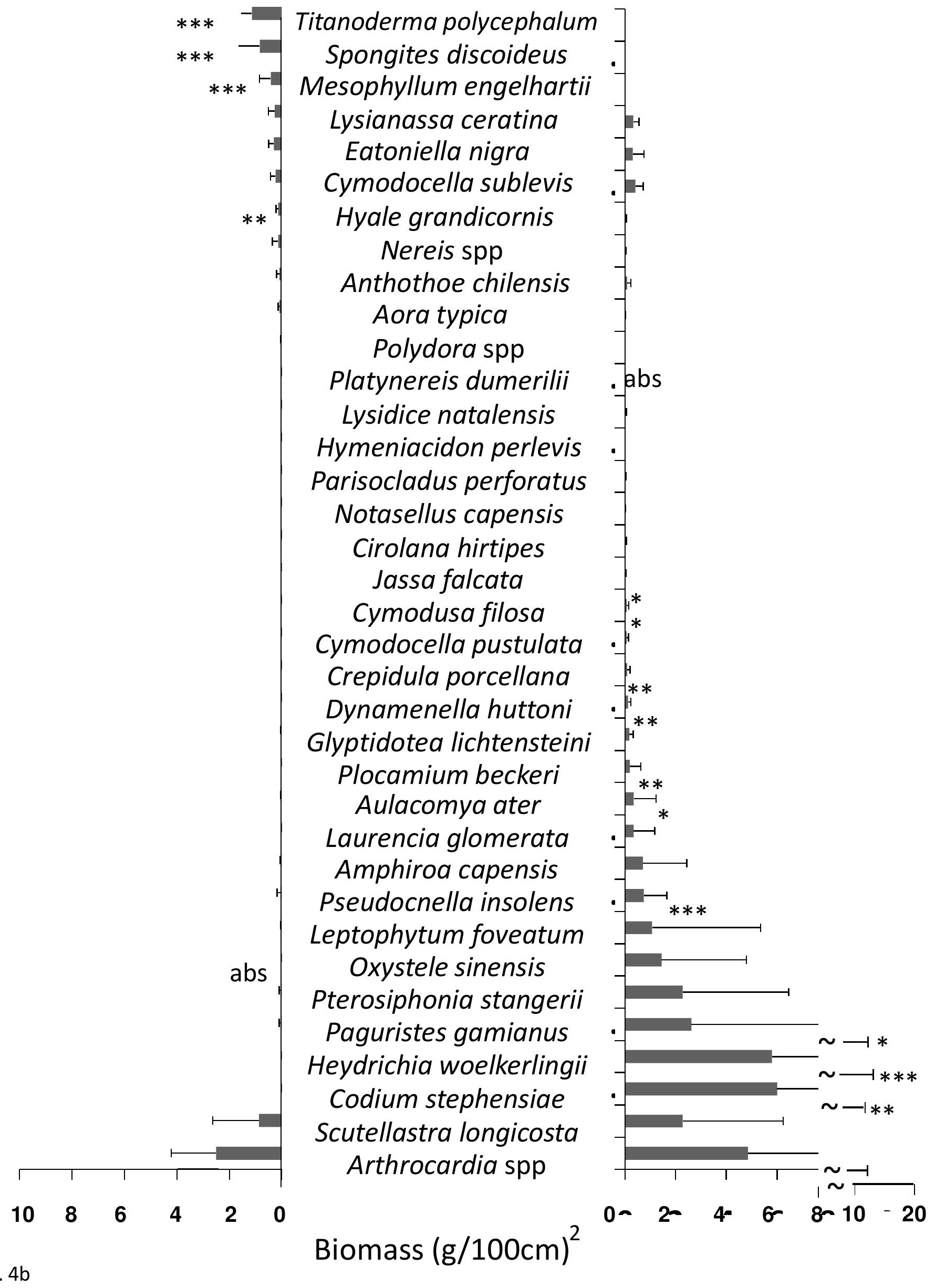


Cape Point

Shell

Rock
Total

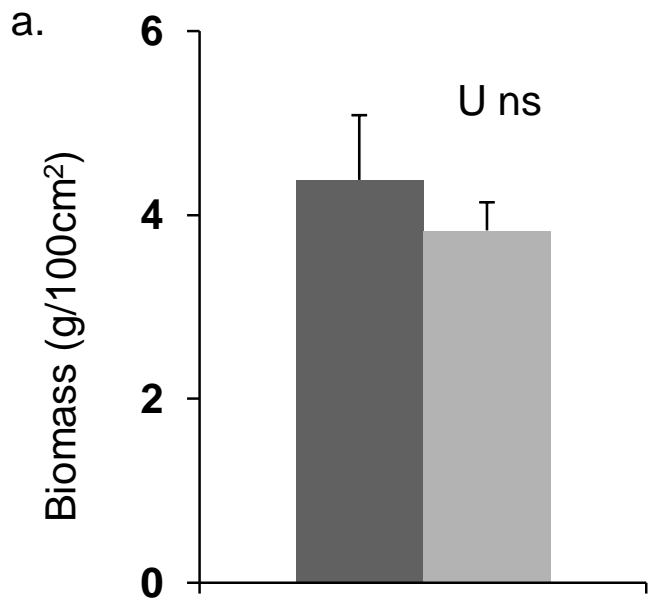

t ns

b.

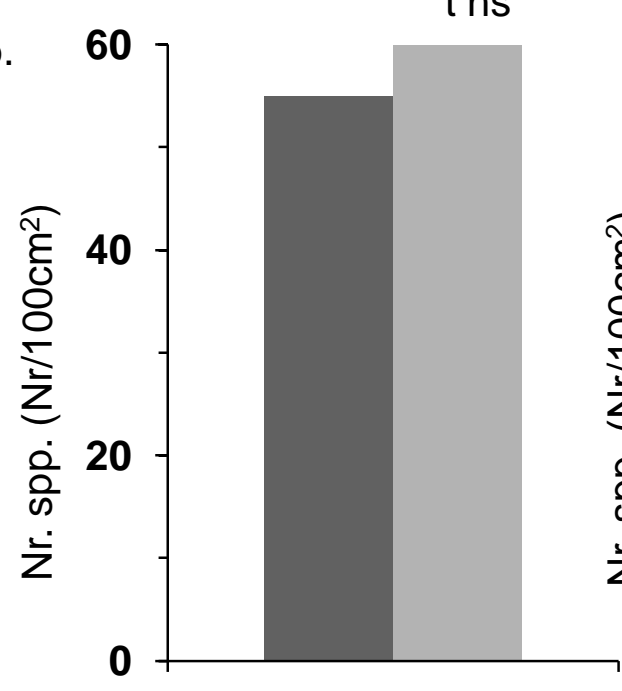

Animal

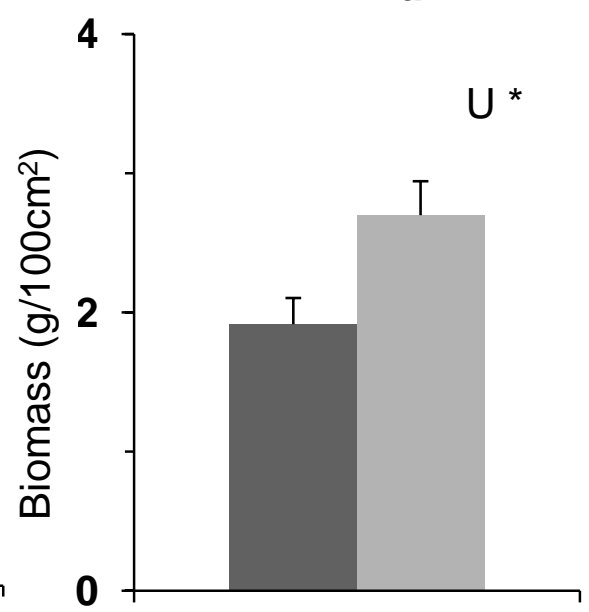

t ns
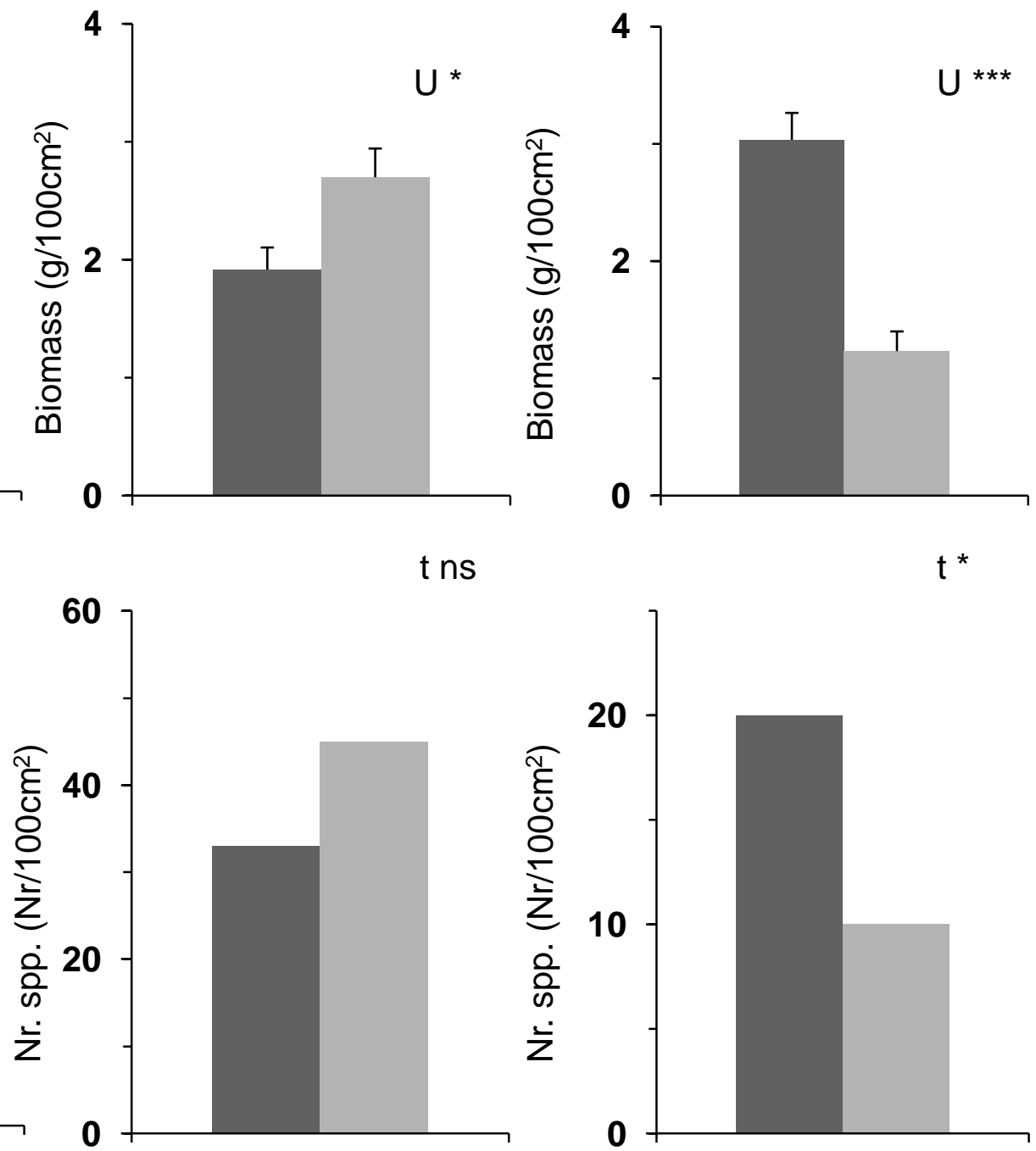

$t^{*}$

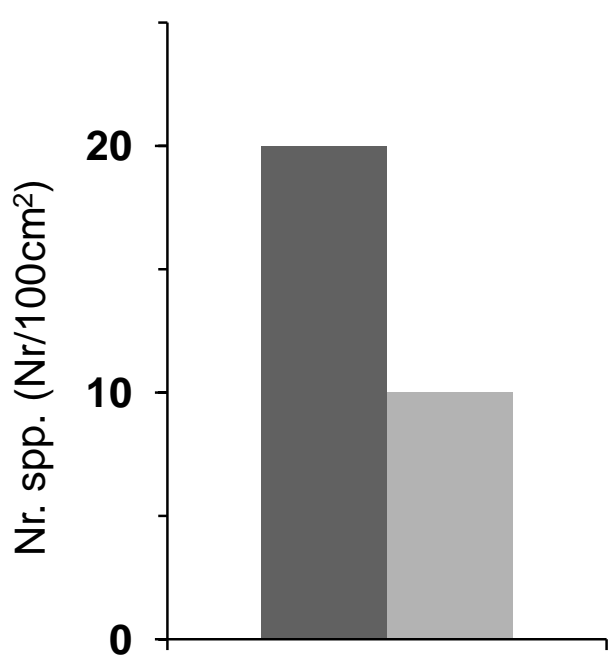

C
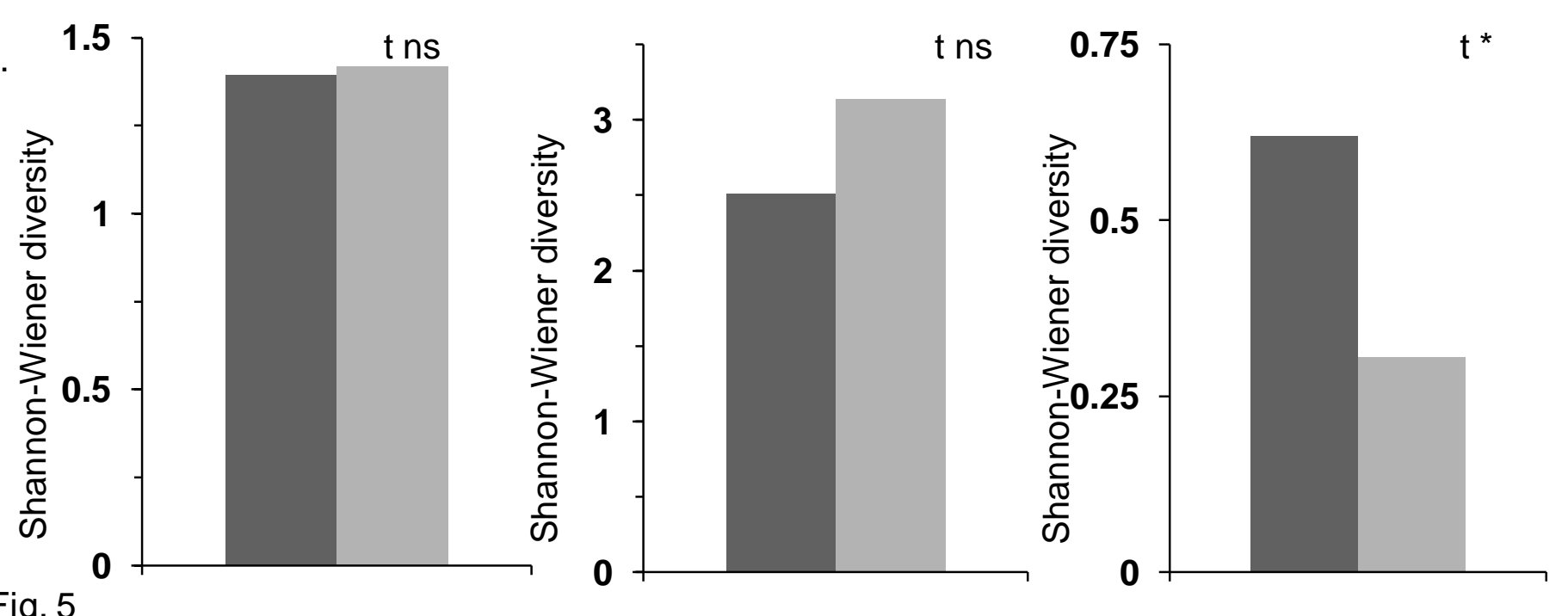

Fig. 5 


\section{Danger Point}

Total

a.

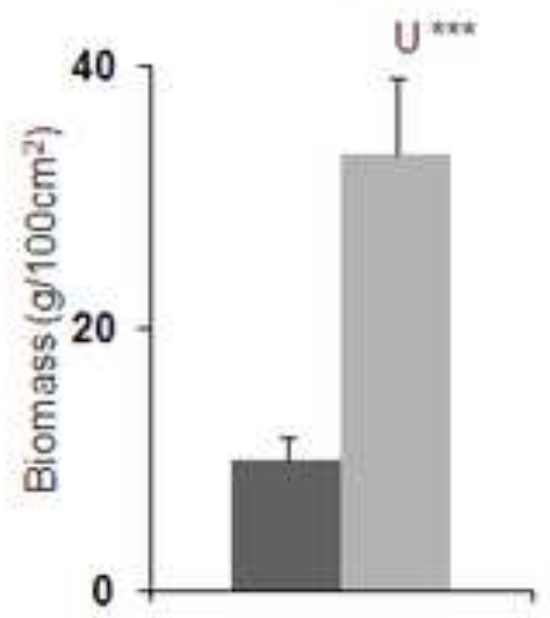

b.

c.
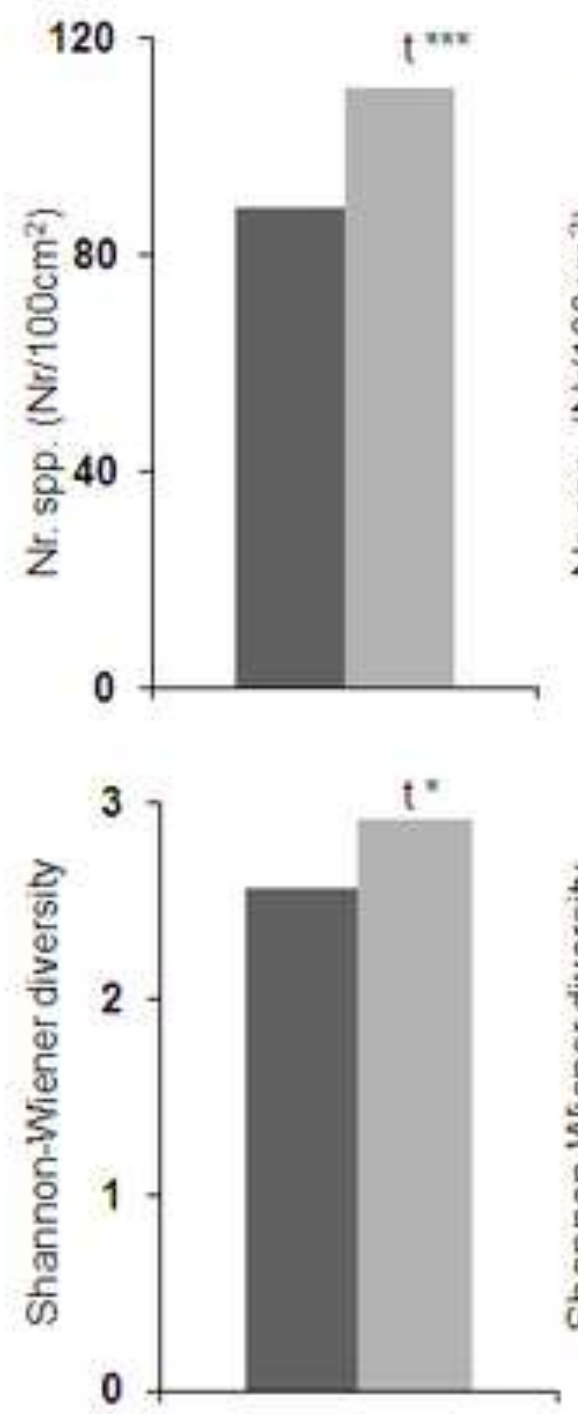

Animal
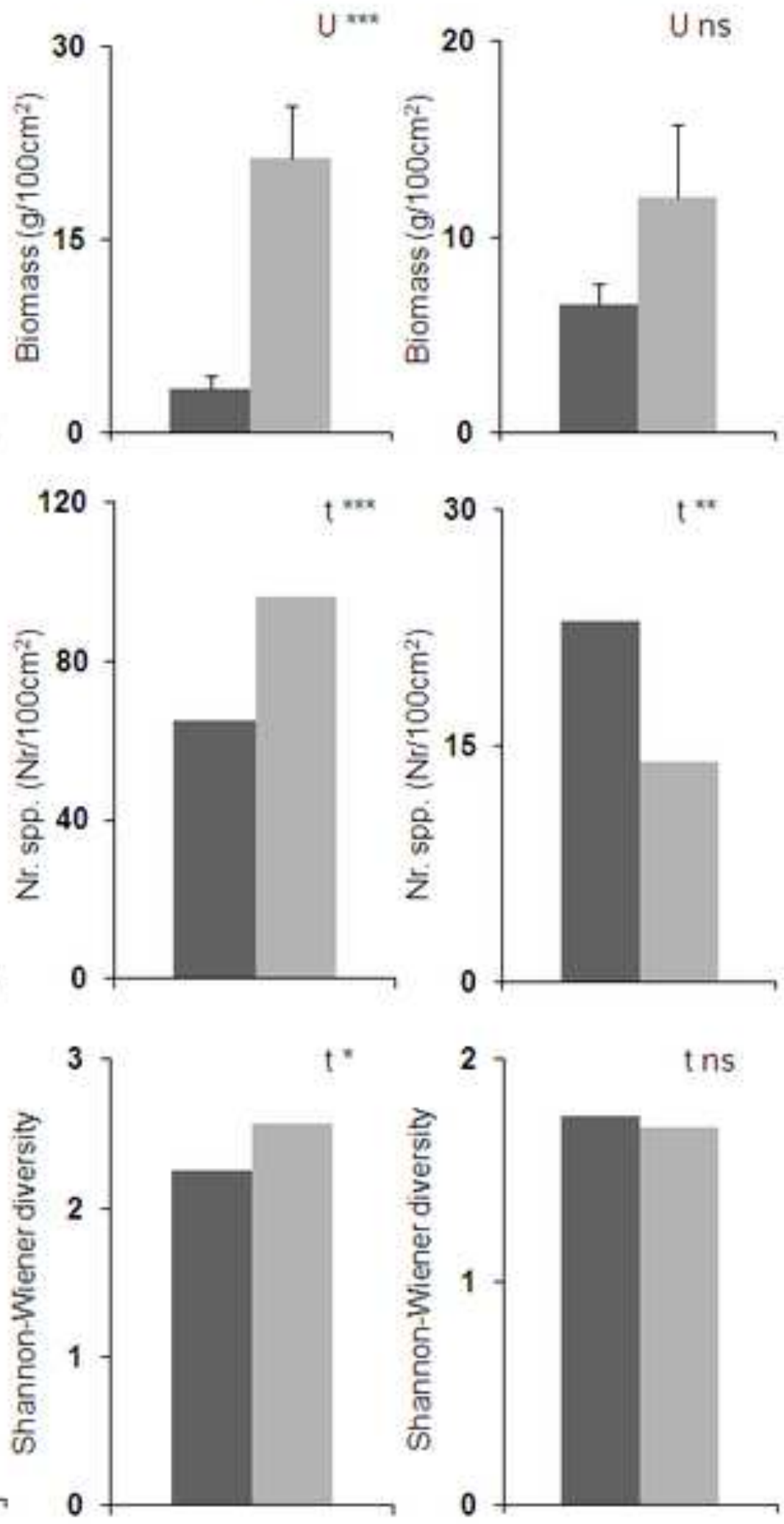

Fig. 6 


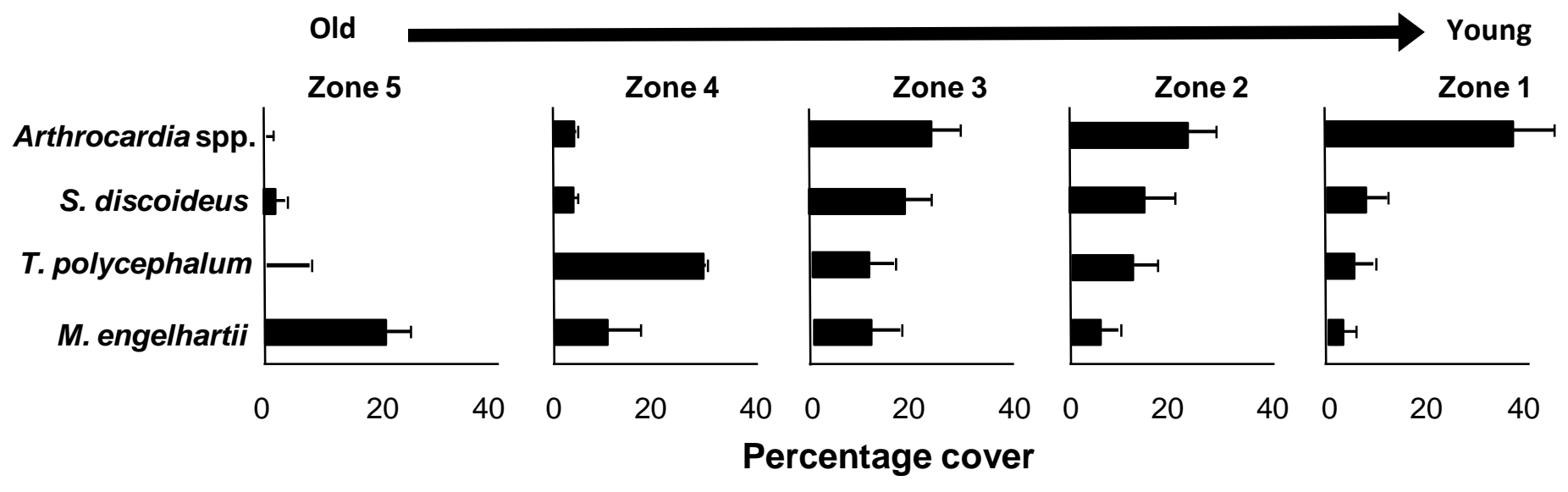

Fig. 7 

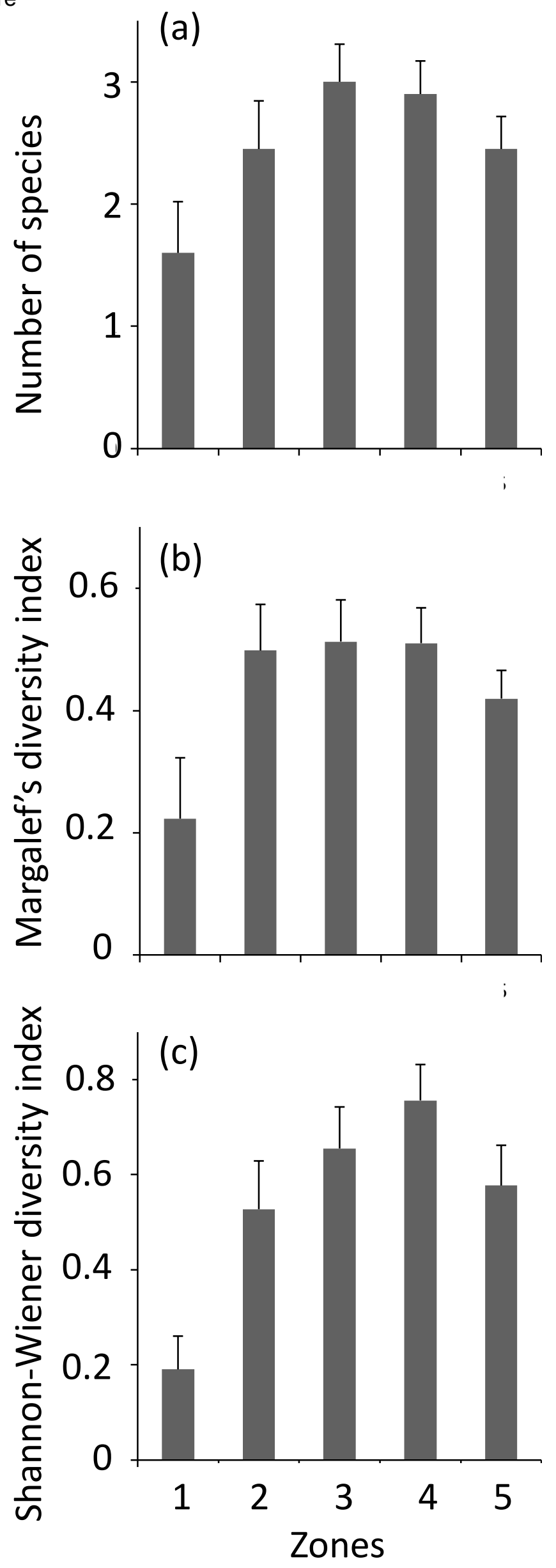

Fig. 8 